\title{
Safe, Easy and Economic Assessment of Patients: A Case of Handmade Stethoscope in HIV Positive at Tertiary Level Hospital in North India
}

Tanmay Tiwari, Subhash Dahiya, Vipin Dhama, Nidhi Pathak, Meenakshi Gaur and Sanjeev Kumar

LLRM Medical College, Anesthesia and Critical Care, Meerut, Uttar Pradesh, India

\begin{abstract}
Stethoscopes are essential tools of the medical profession and because of their universal use, might be a source of microorganisms that cause nosocomial infections. Stethoscopes come in direct contact with numerous patients daily and their disinfection after each use is not an established practice. Several studies in medical literature have demonstrated that many physicians' stethoscopes are contaminated with pathogenic bacteria and could serve as a mode for transmission of infection. In view of contamination and spread of infection by the stethoscope, we have devised a handmade disposable stethoscope which is safe, easy and economical and can be specially used in HIV positive patients.
\end{abstract}

Keywords: Anesthesia; Stethescope; Contamination; Disposable; Safe; Economical; HIV

\section{Background}

The stethoscope is an acoustic medical device for auscultation, or listening to the internal sounds of an animal or human body. A French doctor named Rene Theophile Hyacinthe Laënnec (1781-1826) at the Necker-Enfants Malades Hospital in Paris invented the first stethoscope in 1816 [1].

Stethoscopes are essential tools of the medical profession and because of their universal use might be a source of microorganisms that cause nosocomial infections. Stethoscopes come in direct contact with numerous patients daily and they usually get soiled with blood and blood products during per operative monitoring and their disinfection after each use is not an established practice. In a study of 150 health care workers (50 paramedics, 50 nurses, and 50 doctors), staphylococcus species (mostly coagulase negative) were cultured from $89 \%$ of the participants' stethoscopes, the mean number of colony forming units increasing the longer stethoscopes were not cleaned [2]. There are no studies on the beneficial effect of regularly cleaning stethoscopes on nosocomial infection rates. Nevertheless, regular disinfection should be carried out (at least once daily), as the level of contamination rises from $0 \%$ to $69 \%$ after more than one day without cleaning of the stethoscope [3] Isopropyl alcohol is an effective cleaning agent [4], but may dry out the stethoscope's rubber seals and damage the tubing if used routinely.

The use of the stethoscope in the monitoring of the anesthetized patient can be traced back to Cushing in 1909 [5]. AAPD Guidelines also state that "a precordial/pretracheal stethoscope shall be used for obtaining additional information on heart and respiratory rates and for monitoring airway patency during Level 3 sedations [6,7]."

\section{Methods}

In view of contamination and associated infections, we have devised a disposable stethoscope which can be used as a 'use and throw' device for every HIV positive patients. A $2 \mathrm{yr}$ old male HIV positive patient was posted for urethroplasty under GA for which we used this handmade stethoscope which was safe, economical (usually they range from 250-5000 Rupees, but our was actually free of cost) and was very effective for the case. In our government hospitals where majority of patients are poor and non affording, this device has proved to be very economical and doesn't add to the financial burden of the patient.

\section{Description of Device}

\section{Parts}

It has a tubing made of iv infusion set which is supplied free of cost by government in most of the hospitals, an earpiece which can be taken from any old dumped stethoscope and a diaphragm made from cap of an eye drops bottle which can be found scattered in any ophthalmic OPD.

\section{Things required}

iv set, eye drops bottle cap, earpiece and a micropore and a scissor.

\section{How to make}

Cut iv set in pieces as shown in the picture. Connect eye drops bottle cap to one end and earpiece to another and we have our safe, easy and economical precordial stethoscope ready to use (Figure 1-4).

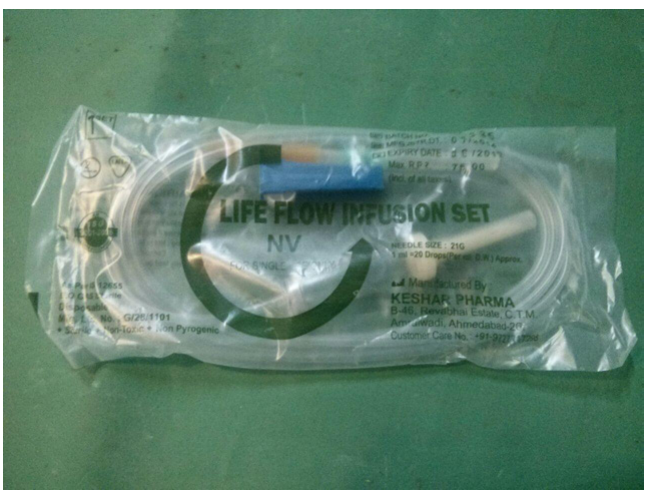

Figure 1: I V flowset.

*Corresponding author: Tanmay Tiwari, LLRM Medical College, Anesthesia and Critical Care, Meerut, Uttar Pradesh, 250004, India, Tel: 919452526270; E-mail: tanmayanesthesia@gmail.com

Received March 31, 2015; Accepted May 01, 2015; Published May 11, 2015

Citation: Tiwari T, Dahiya S, Dhama V, Pathak N, Gaur M, et al. (2015) Safe, Easy and Economic Assessment of Patients: A Case of Handmade Stethoscope in HIV Positive at Tertiary Level Hospital in North India. J AIDS Clin Res 6: 455 doi:10.4172/2155-6113.1000455

Copyright: (c) 2015 Tiwari T. This is an open-access article distributed under the terms of the Creative Commons Attribution License, which permits unrestricted use, distribution, and reproduction in any medium, provided the original author and source are credited. 
Citation: Tiwari T, Dahiya S, Dhama V, Pathak N, Gaur M, et al. (2015) Safe, Easy and Economic Assessment of Patients: A Case of Handmade Stethoscope in HIV Positive at Tertiary Level Hospital in North India. J AIDS Clin Res 6: 455. doi:10.4172/2155-6113.1000455

Page 2 of 2

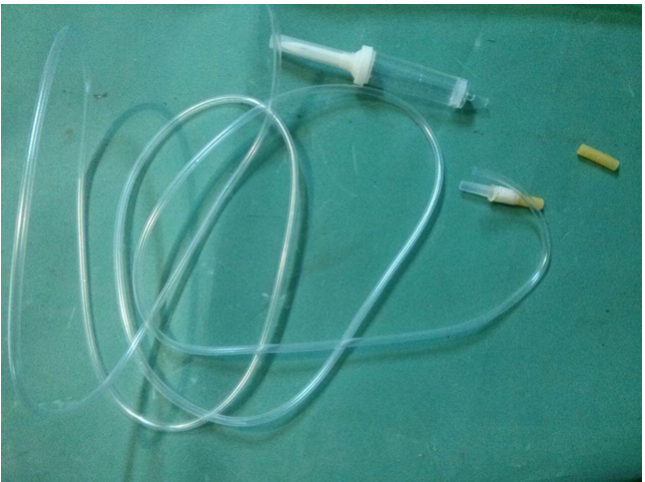

Figure 2: Cut both the ends of IV flow set.

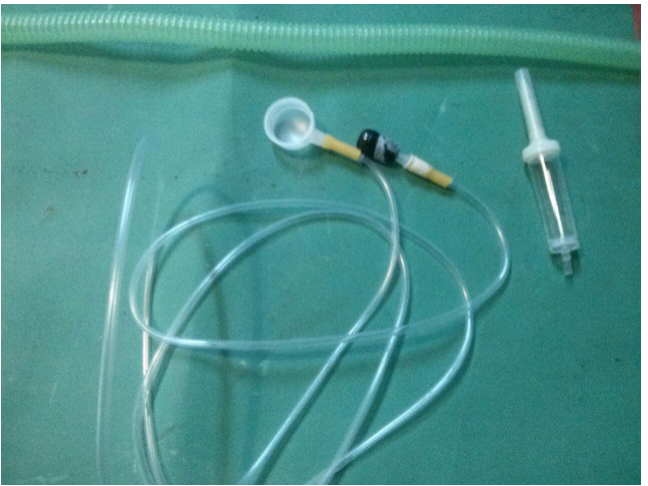

Figure 3: Attach the ear piece and the ophthalmic droper to the two split ends.

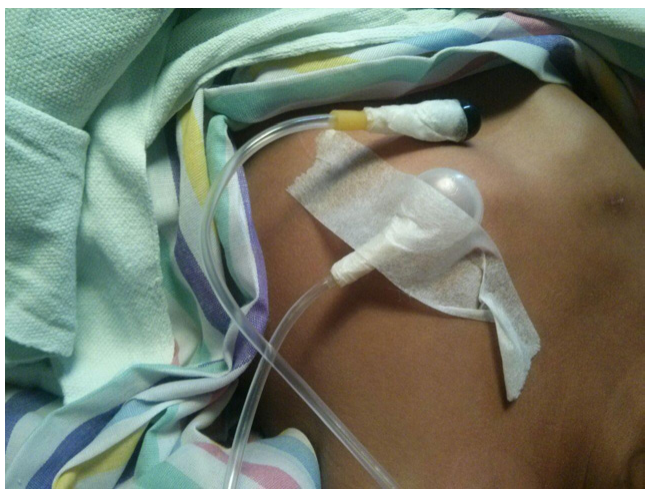

Figure 4: Attach the assembly to use in patients with help of sticking tape.

\section{Conclusions}

As the device is easy to assemble and is cost effective and can be used as an use and throw device for HIV positive patients, it may prove to be beneficial in middle and low income countries without compromising patient safety.

\section{References}

1. Roguin A (2006) Rene Theophile Hyacinthe Laënnec (1781-1826): the man behind the stethoscope. Clin Med Res 4: 230-235.

2. Jones JS, Hoerle D, Riekse R (1995) Stethoscopes: a potential vector of infection? Ann Emerg Med 26: 296-299.

3. Genné D, de Torrenté A, Humair L, Siegrist HH (1996) [Level of stethoscope contamination in the hospital environment]. Schweiz Med Wochenschr 126: 2237-2240.

4. Marinella MA, Pierson C, Chenoweth C (1997) The stethoscope. A potential source of nosocomial infection? Arch Intern Med 157: 786-790.

5. Smith MA, Mathewson JJ, Ulert IA, Scerpella EG, Ericsson CD (1996) Contaminated stethoscopes revisited. Arch Intern Med 156: 82-84.

6. Philip JH, Raemer DB (1986) An electronic stethoscope is judged better than conventional stethoscopes for anesthesia monitoring. J Clin Monit 2: 151-154.

7. Iwasaki J, Vann WF Jr, Dilley DC, Anderson JA (1989) An investigation of capnography and pulse oximetry as monitors of pediatric patients sedated for dental treatment. Pediatr Dent 11: 111-117. 